\title{
El papel del historiador del arte en la restauración monumental: problemática actual y propuestas de futuro
}

\author{
Francesca Tugores Truyol | Universitat de les Illes Balears \\ Miquel Àngel Capellà Galmés | Universitat de les Illes Balears \\ URL de la contribución <www.iaph.es/revistaph/index.php/revistaph/article/view/3454>
}

Es evidente que existe un problema en la integración del historiador del arte en el mercado profesional más allá de la docencia, un hecho que contrasta con el creciente interés por el patrimonio histórico-artístico en el que, por formación, es uno de sus máximos especialistas. Esta problemática se da en varios campos, como el museístico, la gestión cultural o en la crítica de arte. Ahora nos centraremos en el ámbito de la intervención patrimonial $^{1}$.

Entendemos que la intervención del historiador del arte es imprescindible en cualquier actuación de gestión de un bien histórico-artístico, ya no solamente con la realización de un informe preceptivo, sino con su presencia activa en todas las fases del trabajo interdisciplinar ${ }^{2}$. Si bien el titular de una intervención arquitectónica es, por ley y por formación, un arquitecto, las cartas internacionales y varios artículos de la legislación sectorial de patrimonio establecen como base de las intervenciones la identificación y preservación de los valores del elemento, y para ello es primordial que exista un análisis específico realizado desde el conocimiento de especialidad, partiendo de las fuentes primarias.

Para el desarrollo con garantías de un proyecto de intervención patrimonial entendemos que sus responsables deben formar un equipo en el que todos sus miembros arquitecto, historiador del arte, conservador-restaurador, arqueólogo/arqueólogo de la arquitectura y cualquier otro especialista que se considere relevante en cada casose responsabilicen del proyecto desde principio a fin, aunque, evidentemente, con diferentes grados de competencia y dedicación. Ello debería producirse desde la fase de estudios previos (I), en la que el equipo analiza historia, valores, patologías, potencialidades, etc.; continuar en la fase proyectual (II) -en la que intervienen todos sus miembros, aportando reflexiones y directrices al arquitecto, y también redactando proyectos específicos cuando sea necesario-; así como durante toda la ejecución de la obra (III), momento en el que todos realizan un seguimiento y en el que pueden aparecer nuevos valores, que posiblemente conllevaran cambios de proyecto. Para acabar, es fundamental que el equipo por completo participe de la redacción de la memoria final (IV), en la que se recogerá el proceso de trabajo completo y la información de valor científico, sin olvidar la transmisión y difusión del conocimiento histórico recuperado a la sociedad. No puede obviarse, además, que los profesionales de este equipo ideal deberán estar dotados de una gran vocación de diálogo, de voluntad de labor en grupo, y de la correspondiente dosis de ética profesional.

En realidad, en pocas ocasiones se reproduce este esquema de intervención y documentación, y lo más habitual es que el historiador del arte, si se le encuentra, tenga un papel de mero documentalista. Se han hecho varios intentos por identificar la problemática y proponer vías de futuro (BORRÁS, 1989-1990: 7-12; CASTILLO, 2009: 1-13; LACUESTA, 2007: 1-35), en los que se constata una situación caracterizada por la indefinición, la falta de consideración y de regulación, que se debe a múltiples circunstancias que es necesario analizar para poder vehicular soluciones de futuro. Éstas son:

1. Falta de conciencia, en general, de la importancia de conocer todos los valores, visibles y ocultos, conocidos e inéditos, antes de plantear una intervención en un bien cultural. Es imprescindible una investigación previa para descubrir los valores y potencialidades, para a continuación plasmarlos en unos criterios de intervención, que pueden incluir aspectos del bien inmueble y de su 
a debate Historiadores del arte ¿para qué? Una titulación en busca de una profesión | coordina José Castillo Ruiz

entorno, así como bienes muebles vinculados o aspectos de patrimonio inmaterial. Esta es una de las tareas del historiador del arte, sobre la cual debe basarse el proyecto de intervención.

2. Falta de consideración y desconocimiento de la disciplina, así como de lo que puede aportar al proceso. En consecuencia, en muchas ocasiones, sus funciones son asumidas por otros profesionales del patrimonio (intrusismo profesional).

3. Escasa presencia de historiadores del arte en los organismos, instituciones y administraciones responsables de la tutela.

4. Falta de preparación de los titulados en metodología aplicada. Falta de referentes y documentos sobre el papel que deben asumir en los equipos interdisciplinares. El corpus bibliográfico es muy reducido, ya que los informes historico-artísticos no se publican o bien son transformados en artículos científicos, perdiéndose parte de la información aplicada.

5. Ausencia de regulación en la mayoría de las comunidades, sobre su presencia y papel en los proyectos de gestión patrimonial.

6. Falta de documentos de referencia -más allá de las meritorias aportaciones de autores concretos- elaborados por entidades o comités oficiales que detallen sobre el papel los objetivos, el método y las diferentes variables del trabajo del historiador del arte en la gestión patrimonial.

7. Ausencia de organismos específicos de colegiación para los historiadores del arte en algunas comunidades.

8. Todo ello genera una situación de no profesionalización del historiador del arte, que muy raramente forma parte de equipos de trabajo y empresas especializadas, por lo que, cuando se le requiere, no se localiza una plantilla de profesionales autónomos acostumbrados a la práctica de la disciplina, ni a solucionar problemas con los tiempos y dinámicas que requieren este tipo de proyectos.

Las soluciones, como hemos avanzado, empiezan por nosotros mismos, los historiadores del arte, que debemos debatir, asumir y reflejar el papel que consideramos que ha de tener la disciplina a nivel profesional. A partir de esta reflexión se podrían articular varias líneas de trabajo:

- Inclusión, en los planes de estudio de toda una serie de contenidos metodológicos para su aplicación en el marco profesional, tanto como materia específica como transversal, intentando dar solución o respuesta a problemas patrimoniales.

- Creación de foros de debate y elaboración de documentos de referencia consensuados a nivel estatal, que recojan los criterios y la metodología.

- Iniciativas de colegiación y defensa del campo profesional, tales como secciones específicas de historiadores del arte en los colegios de licenciados y doctores. Desde ellos se puede trabajar por la presencia de titulados en los equipos profesionales y administraciones.

- Actuaciones de divulgación, a distintos niveles, sobre la importancia del trabajo del historiador del arte en determinados ámbitos, para ir supliendo la "invisibilidad social" que habitualmente caracteriza la profesión. 
a debate Historiadores del arte ¿para qué? Una titulación en busca de una profesión | coordina José Castillo Ruiz

\section{NOTAS}

1. La presente aportación forma parte de la transferencia de conocimientos del proyecto de investigación Ciudades históricas $y$ paisaje construido en Mallorca: Análisis de sus valores y estado de protección jurídica. Una propuesta de reordenación (HAR2012-36193), financiado por el Ministerio de Economía y Competitividad.

2. Para el debate sobre la especificidad de su aportación en correlación con otras disciplinas, ver el punto 1 del texto de Castillo Ruiz, que alude a la "competencia profesional exclusiva e intransferible en relación al estudio de bienes histórico-artísticos en tres ámbitos: descripción formal, análisis histórico-artístico y valoración patrimonial" (CASTILLO, 2009: 5).

\section{BIBLIOGRAFÍA}

- BORRÁS GUALIS, G. M. (1989-1990) A modo de presentación: El papel del historiador del arte en la conservación y restauración de monumentos y obras artísticas. Artigrama, n. ${ }^{\circ}$ 6-7, 1989-1990, pp. 7-12

- BorRÁs GuAliS, G. M. (2012) Historia del Arte y Patrimonio Cultural: una revisión crítica. Zaragoza: Prensas Universitarias de Zaragoza, 2012

- CASTILlO RUIZ, J.; GÓMEZ JIMÉNEZ, J. J. (2009) Propuesta para una reglamentación legal de la actividad profesional de la Historia del Arte en el campo de la protección del Patrimonio Histórico. e-rph, n. ${ }^{\circ}$ 5, 2009, pp. 1-13

- GARCíA CUETOS, M. P. (1987) El Historiador del Arte ante el proceso de Restauración Monumental. Liño: Revista anual de historia del arte, n. ${ }^{\circ} 7,1987$, pp. 203-216

- GómeZ ROBLES, L. (2010) Los valores del monumento restaurado. Una aproximación a la restauración científica. Revista ph, n. ${ }^{\circ} 75,2010$, pp. 80-93

- $\quad$ LACUESTA CONTRERAS, R. (2007) El Historiador del Arte como agente responsable de la conservación de la obra artística. e-rph, n. ${ }^{\circ} 1,2007$, pp. 1-35 